\title{
International meeting: new diagnostic tests are urgently needed to treat patients with Chagas disease
}

\author{
Reunião internacional: novos testes diagnósticos são necessários urgentemente \\ para tratar pacientes com doença de Chagas
}

\author{
Médecins Sans Frontières. Campaign for Access to Essential Medicines \\ Rio de Janeiro, RJ, August 30-31, 2007
}

\begin{abstract}
Trypanosoma cruzi infection is often not detected early on or actively diagnosed, partly because most infected individuals are either asymptomatic or oligosymptomatic. Moreover, in most places, neither blood banks nor healthcare units offer diagnostic confirmation or treatment access. By the time patients present clinical manifestations of advanced chronic Chagas disease, specific treatment with current drugs usually has limited effectiveness. Better-quality serological assays are urgently needed, especially rapid diagnostic tests for diagnosis patients in both acute and chronic phases, as well as for confirming that a parasitological cure has been achieved. Some new antigen combinations look promising and it is important to assess which ones are potentially the best, together with their requirements in terms of investigation and development. In August 2007, a group of specialized researchers and healthcare professionals met to discuss the state of Chagas infection diagnosis and to build a consensus for a plan of action to develop efficient, affordable, accessible and easy-to-use diagnostic tests for Chagas disease. This technical report presents the conclusions from that meeting.
\end{abstract}

Key-words: Trypanosoma cruzi. Chagas infection. Rapid diagnostic tests. Serology. Chagas disease.

\section{RESUMO}

A infecção pelo Trypanosoma cruzi não é comumente detectada cedo ou diagnosticada ativamente, em parte porque a maioria dos infectados é assintomática ou oligossintomática e nem os bancos de sangue nem as unidades de saúde oferecem, na maioria dos lugares, nem a confirmação do diagnóstico nem o acesso ao tratamento. Habitualmente, quando os pacientes apresentam manifestações clínicas avançadas da doença crônica 0 tratamento específico com os medicamentos atuais tem efetividade limitada. São necessárias urgentemente provas sorológicas de melhor qualidade, e em especial provas diagnósticas rápidas, para diagnosticar pacientes na fase aguda e crônica, assim como para confirmar a cura parasitológica. Algumas novas combinações de antígenos são promissoras e é importante avaliar as potencialmente melhores, assim como as suas necessidades em nível de pesquisa e desenvolvimento. Em agosto 2007, um grupo de pesquisadores especializados e profissionais da área da saúde se reuniu para discutir a situação do diagnóstico da infecção chagásica e elaborar um consenso sobre um plano de ação em prol do desenvolvimento de testes diagnósticos eficientes, acessíveis e fáceis de usar. Este informe técnico apresenta as conclusões da reunião.

Palavras-chaves: Trypanosoma cruzi. Infecção chagásica. Testes diagnósticos rápidos. Sorologia. Doença de Chagas.

Trypanosoma cruzi infection is often not detected early on or actively diagnosed, partly because most infected individuals are either asymptomatic or oligosymptomatic. Moreover, in most places, neither blood banks nor healthcare units normally offer diagnostic confirmation or treatment access. By the time patients present clinical manifestations of advanced chronic Chagas disease, the specific treatment with current drugs usually has limited effectiveness. As a typical neglected illness, in most places Chagas disease has remained silent and silenced. International initiatives to combat Chagas disease have focused mostly on vector and transfusional control. Active screening and treatment of patients have rarely received the importance they deserve.
The high infection/disease prevalence in countries like Bolivia highlights the need for a change in strategy.

Because of the situation regarding Chagas disease that has been described, Médecins Sans Frontières (MSF) has been working with patients suffering from Chagas disease since 1999 (with more than 2,000 patients treated). Currently, MSF provides medical care to patients suffering from Chagas disease in two Bolivian projects, in Sucre and Cochabamba, where children and young adults are treated. In Bolivia and Guatemala, patients seen by MSF doctors in rural and peripheral urban areas have been diagnosed using a combination of serological tests. The recent introduction of rapid diagnostic tests (RDTs) has allowed

Address to: Dra. Ângela C. V. Junqueira. Laboratório de Doenças Parasitárias, Instituto Oswaldo Cruz/Fiocruz. Av. Brasil, 4365 - Manguinhos. $21040-360$ Rio de Janeiro, RJ, Brasil. Tel: 5521 2280-3740; Fax: 5521 2280-3740

Recebido para publicação em: 12/12/2007

Aceito em: 07/04/2008 
MSF teams to assess patients through field diagnosis and active screening. However, the existing rapid tests have so far not fulfilled the diagnostic needs ${ }^{14}$.

Better quality RDTs are urgently needed: tests that are proven to be effective and affordable for diagnosing patients in both the acute and chronic phases, as well as for confirming that a parasitological cure has been achieved. Some new antigen combinations look promising: it is important to discuss which of these are the best possible antigen combinations and what their requirements are, with regard to investigation and development. In August 2007, a group of specialized researchers and healthcare professionals met in Rio de Janeiro, Brazil, to discuss the state of Chagas infection diagnosis and to build a consensus for a plan of action to develop efficient, affordable, accessible and easy-to-use diagnostic tests for Chagas disease. This technical report presents the conclusions from that meeting.

\section{SEROLOGICAL DIAGNOSIS OF TRYPANOSOMA CRUZI INFECTION}

In the short initial acute phase, or in cases of reactivation due to immunosuppression, high parasitemia is observed and the diagnosis of Trypanosoma cruzi infection is based on direct parasitological tests. On the other hand, because of low parasitemia, in the chronic phase, the diagnosis is based on detection of antibodies, which are present in most patients in differing concentration titers, although their relationship with the degree of morbidity has not yet been established ${ }^{316}$.

In the chronic phase, the serological diagnosis is usually performed using conventional commercial tests: indirect immunofluorescence assay (IFA), enzyme-linked immunosorbent assay (ELISA) and indirect hemagglutination assay (IHA). The main advantages of IFA are its high sensitivity, its qualitative results (describing the immunofluorescence pattern) and quantitative results (titers). The disadvantages of IFA are the need for an expensive fluorescence microscope, the dependence of its reliability on subjective reading and microscopist expertise, and its low processing speed. The main advantages of ELISA are its high sensitivity and specificity, depending on the antigen to be detected and the cutoff used, its ability to process large quantities of samples rapidly and its objective quantitative results. The disadvantages of ELISA are the need for a cold chain (samples at $-20^{\circ} \mathrm{C}$ and reagents at $2-8^{\circ} \mathrm{C}$ ), a skilled technician and rather expensive equipment and supplies. The main advantages of IHA are its relatively fast results (2h), lack of need for sophisticated equipment and its quantitative results (titers). The disadvantages of IHA are the lower sensitivity that it presents in relation to IFA and ELISA, the possibility of false positive results (especially in relation to poor storage, transportation conditions and even the intrinsic commercial kit performance), its low reproducibility, its variable reliability dependant on subjective reading, and the need for a cold chain for kit storage, as with IFA and ELISA ${ }^{10}$.

According to World Health Organization (WHO) recommendations, individual diagnoses have to be based on two conventional tests based on different principles and detecting different antigens. The conventional tests use a complex mixture of parasite antigens (IHA and ELISA) or the entire parasite itself (IFA). This increases the sensitivity, even when the antibody levels are low, but decreases the specificity, because of the presence of cross-reactions between Trypanosoma cruzi and Leishmania spp. Other examples of difficult diagnostic situations are the low levels of parasitemia involving Trypanosoma cruzi group I that are usually found in the Amazon region, along with other frequent coinfections and the presence of other autoimmune diseases. In case of doubtful results (values on the cutoff line or within the indeterminate zone) or discordant results, the tests can be repeated and a third test, preferably a confirmatory one, can also be used ${ }^{15}$.

At the present moment, there are some candidates for confirmatory tests: radioimmunoprecipitation assays (RIPA), immunoblot assays using recombinant antigens and Western blot assays using trypomastigote excreted-secreted antigens (TESA-blot).

RIPA, a highly sensitive and specific test with easily interpreted results, was developed two decades ago and has been suggested for use as a confirmatory test in the United States. Although RIPA has been used in more than 20 research projects as a confirmatory assay, its sensitivity and specificity have not been systematically validated. Moreover, its technical complexity and the fact that it is labor-intense and expensive and involves radioactivity would make its widespread use outside of research settings difficult ${ }^{45}$.

The INNO-LIA $®$ Chagas assay is a type of commercially available immunoblot assay using seven recombinant and synthetic antigens: CRA, FRA, Tc-24, SAPA, MAP, TcD and Ag39, which are coated at separate locations onto a single nylon membrane strip. This physical separation of the different antigens prevents sterical hindrance during antibody binding, but this may be a problem if a mixture of the antigens is used in a single well of an ELISA plate. It presents high sensitivity and specificity, with no cross-reactions with leishmaniasis, but it is difficult to interpret the results and its high cost has limited its use $\mathrm{e}^{781112}$

Recently, a new combination of four recombinant antigens has been proposed (FP10, FP6, FP3 and TcF), also using an immunoblot principle. Each of these antigens is composed of several antigenically distinct regions and includes both repetitive and non-repetitive sequences. Each antigen is coated as a discrete line on a nitrocellulose strip. This assay presents high levels of sensitivity and specificity, and it is potentially suitable for use as a confirmatory test. It has already been evaluated commercially and the small number of bands facilitates interpretation through visual reading, without the need for laboratory instruments ${ }^{2}$.

The performance of the TESA-blot test for diagnosing Trypanosoma cruzi infection is related to the presence of shed acute-phase antigens (SAPA) in the acute phase and a band of 150$160 \mathrm{kDa}$ in the TESA medium in the chronic phase. Differently from conventional tests detecting anti-Trypanosoma cruzi epimastigote antibodies, TESA-blot detects molecules that are only present in trypomastigote forms, the evolutionary form that is found in mammals (including humans) and is present in all Trypanosoma 
cruzi strains studied up to now (about 50). As TESA-blot presents high sensitivity and specificity, without cross-reactions with either visceral leishmaniasis or Trypanosoma rangeli, and it is apparently able to resolve more than $95 \%$ of serologically doubtful cases, it has been proposed as a confirmatory test ${ }^{13}$.

Responding to a new market need, rapid diagnostic tests (RDTs) have recently come onto the market, and some national Chagas disease programs, such as in Bolivia, have already included them in their national protocols for diagnosing Trypanosoma cruzi infection. However, the few RDTs available up to now do not fulfill the current field diagnostic needs. The main advantages of the RDTs identified so far have been: rapid processing (only a few minutes); no need for a cold chain, lab reagents, laboratory equipment or instruments; shelf life of 18 months at room temperature; no need for specialized laboratory technical skills; possibility of use on different types of samples (blood, serum or plasma); devices available in sealed pouches for individual use. On the other hand, the disadvantages of RDTs that have been identified include: their screening test category (not a diagnostic category - neither conventional nor recommended by WHO); some proportion of difficult-to-interpret results (weakly or very weakly result lines); non-quantitative results and consequent limitations on follow-up after treatment; few RDTs yet on the market; better specificity than sensitivity, which constrains the screening capacity; lack of performance assessment under different field conditions (temperature, humidity and altitude) with different Trypanosoma cruzi and human populations; and the high cost per device (without taking into account laboratory personnel, quality control and reagent storage) ${ }^{69}$.

\section{CONCLUSIONS AND RECOMMENDATIONS CONCERNING CHRONIC CHAGAS DISEASE DIAGNOSIS}

I. In Latin America, diagnoses using the conventional tests are made in big urban centers, but huge numbers of infected patients are in medium-sized towns and rural areas where there are neither any equipped laboratories nor any qualified human resources. The specific constraints in remote or poor areas are: the complexity of the protocols, which require at least two patient visits to the health center/laboratory; the technology needed (electricity and equipment); availability of qualified human resources; lack of or difficulty in access; delays in obtaining results, with consequent patient dropouts; and the high costs. On the other hand, when the conventional tests are used in rural or remote areas, it may be impossible to implement them or they may lose their published high sensitivity and specificity characteristics that were achieved under reference laboratory conditions.

II. The participants at the meeting agreed that the current approaches are insufficient to respond to the urgency of the global Chagas challenge and they call upon governments, intergovernmental agencies, researchers, diagnostic test and drug developers, non-governmental organizations and founders to take action in certain key areas:
1. Accelerate development of high-quality rapid diagnostic tests for Chagas disease to reinforce the diagnostic capacity in poorly resourced settings, simplify diagnostic algorithms and facilitate access to treatment.

2. Accelerate development of new generations of tests, with high sensitivity and specificity, for diagnosis of Trypanosoma cruzi infection, follow-up of patients after treatment and rapid cure verification.

3. Accelerate discovery of new biomarkers using new technologies and increase sustainable funding for Chagas research and discovery activities and product development, as a matter of political prioritization.

4. Commit to global Chagas research and discovery, sustained by strong political leadership to improve collaboration between scientists, test developers and care providers, in both rich and poor countries, for the global priority research agenda that is urgently needed for Chagas disease, and with a new model based on collaboration, sharing of data and coordination of efforts.

5. Take new approaches to research and discovery, because the lack of development of Chagas tests comes from the failure of the existing mechanisms based on profit-driven research.

III. It is not possible to treat patients without diagnosis; serological diagnosis is an important entry point, and research and discovery may have a key role in specific remote areas or in specific areas where access to diagnosis does not exist. The desirable research and discovery characteristics should include the following:

1. Rapidity in carrying out tests (without any need for equipment or instruments).

2. Capacity for also performing tests on whole blood.

3. Two-test strategy: firstly a test with high sensitivity (screening test) and secondly a test with high specificity (confirmatory test), using the same device if possible.

4. Detection of specific acute-phase antibodies.

5. Good performance in different Trypanosoma cruzi group regions.

6. Ideally, with quantifiable results for patient follow-up.

7. Stability under field conditions (temperature up to $40^{\circ} \mathrm{C}$, humidity from 20 to $90 \%$, altitude up to 4,000 meters), allowing storage for at least 18 months before use.

8. Avoidance of blood sample shipment through using RDTs.

9. Maintenance of reactivity lines for several months (until eventually checking).

10. Minimal user training required.

11. Validation using field samples and studies in endemic areas (multicenter studies).

12. Patient treatment made possible based on interpreting their test results.

13. Simplified algorithms, in relation to those used at present, making them more practical and field friendly. 
IV. In order to assess commercially produced RDT tests for whole blood, it is recommended that a three-stage comparative study should be conducted: a) collection of all the available information from the producers and from the scientific literature (foundation for good research projects and ethical committee procedures); b) testing on all kits with a serum panel in at least two different reference laboratories, one north of and the other south of the Amazon basin, in order to get comparative sensitivity and specificity information from them; c) testing on the selected kits with appropriate characteristics, in a prospective multicenter field study, with field groups working north and south of the Amazon basin and, preferably, also in the Amazon basin itself, where at the present moment outbreaks and isolated cases of oral and vector transmission are being detected.

V. Trypomastigote excreted-secreted antigens that were described in 1996 and are free from patenting have so far been used by several scientific groups in different regions, using the ELISA and western blot formats. It is proposed to gather together all the available commercial and economic information generated by interested producers until now. It is also proposed that a complete meta-analysis should be performed on the protocols applied and the sensitivity and specificity results obtained, in order to identify strong and weak points relating to their commercialization. Finally, more studies are required to check on the possibility of using them for RD'T support.

VI. At the present moment, different names are given to similar Trypanosoma cruzi antigens. A nomenclature consensus is needed in order to facilitate worldwide information sharing.

VII. All commercial kits should inform their molecule compositions (Trypanosoma cruzi recombinant proteins or purified molecules) and sporadic changes during their lifetimes because of their important implications for day-to-day serological diagnosis and for comparative studies that are planned to assess commercially produced diagnostic kits. For this purpose and for promoting the development of new diagnostic kits, it is necessary to keep a permanently open channel of communication with worldwide producers.

VIII. Much has been done to advance the identification of Trypanosoma cruzi antigens. At the present moment, two important steps are identified: to work towards choosing the best possible combinations of existing antigens; and then to organize multicenter evaluations on these combinations, in order to expand their possible uses.

IX. The present challenges relating to cure verification include: the choice between serological and parasitological tests, with neither an easy nor a rapid answer; complexity of protocols; technology needed; technical challenges with present markers; lack of economic interest among producers; impossibility of detecting reinfections; time gaps and consequent patient dropouts; and unknown outcomes, leading to frustration among physicians and patients, thus jeopardizing new treatments. The present difficulty in cure verification is recognized especially after etiological treatment during the chronic phase. Consequently, there ought to be a test available to demonstrate within a short time that a cure has been achieved, or that there is a trend towards curing the disease.

$\mathbf{X}$. The meeting participants welcome the resolution of the recent World Health Organization Consultation on International Biological Reference Preparations for Chagas Diagnostic Tests, in Geneva, on July 2-3, 2007, proposing the development of International Biological Reference Preparations for antibodies against Trypanosoma cruzi for use in the quality control of diagnostic tests, and enabling appropriate standardization of the tests at global level, as well as correct clinical diagnosis and blood screening.

XI. The meeting participants welcome the Global Network for Chagas disease Elimination (GNChE), which was launched at the recent World Health Organization meeting: Revisiting Chagas disease: from a Latin American bealth perspective to a global health perspective, in Geneva, on July 4-6, 2007, and they propose regular communication with the coordinators of the Technical Groups on Diagnostic test(s) for screening and diagnosis of Trypanosoma cruzi infections and on Prevention and control of congenital transmission and case management of congenital and non-congenital infections (Case-finding, diagnosis and treatment strategies at different health care levels that can be applied in endemic and non-endemic countries), in order to move forward in the best communicative and synergic way.

\section{PARTICIPANTS}

Caryn Bern (Division of Parasitic Diseases, National Center for Infectious Diseases, Centers for Disease Control and Prevention, Atlanta, USA)

José Rodrigues Coura (Parasitic Diseases Laboratory, Oswaldo Cruz Institute, Oswaldo Cruz Foundation, Rio de Janeiro, Brazil)

Samuel Goldenberg (Molecular Biology Institute of Paraná, Curitiba, Paraná, Brazil)

Felipe Guhl (Tropical Microbiology and Parasitology Investigation Canter, University of the Andes, Bogotá, Colombia)

Angela Cristina Verissimo Junqueira (Parasitic Diseases Laboratory, Oswaldo Cruz Institute, Oswaldo Cruz Foundation, Rio de Janeiro, Brazil)

Myriam Lorca (School of Medicine, University of Chile, Santiago, Chile)

Alejandro 0 Luquetti (School of Medicina, Federal University of Goiás, Goiânia, Goiás, Brazil)

Isabela Ribeiro (Drugs for Neglected Diseases Initiative, Rio de Janeiro, Brazil)

Amadeo Sáez-Alquezar (Panel Advisors \& Quality Control, São Paulo, Brazil) 
Faustino Torrico. (University Center for Tropical Medicine, Higher University of San Simón, Cochabamba, Bolivia)

Eufrosina Setsu Umezawa (Protozoology Laboratory, Tropical Medicine Institute of São Paulo, São Paulo, Brazil)

Brian Ward (McGill Center for Tropical Diseases, Montreal General Hospital, Quebec, Canada)

Pedro Albajar-Viñas (Parasitic Diseases Laboratory, Oswaldo Cruz Institute, Oswaldo Cruz Foundation, Rio de Janeiro, and Médecins Sans Frontières, Rio de Janeiro, Brazil.

Gabriela Chaves (Campaign for Access to Essential Medicines, Médecins Sans Frontières Brazil/Belgium, Rio de Janeiro, Brazil)

Laurence Flevaud (Médecins Sans Frontières Spain, Barcelona, Spain)

Javier Goiri (Médecins Sans Frontières Spain, La Paz, Bolivia)

Martine Guillerm (Campaign for Access to Essential Medicines, Médecins Sans Frontières, Geneva, Switzerland)

Unni Krishnan Karunakara (Campaign for Access to Essential Medicines, Médecins Sans Frontières, Geneva, Switzerland)

Michel Lotrowska (Campaign for Access to Essential Medicines, Médecins Sans Frontières, Rio de Janeiro, Brasil)

Simone Rocha (Médecins Sans Frontières Brazil/Belgium, Rio de Janeiro, Brazil)

Martine Usdin (Campaign for Access to Essential Medicines, Médecins Sans Frontières, Geneva, Switzerland)

\section{REFERENCES}

1. Caballero ZC, Sousa OE, Marques WP, Sáez-Alquezar A, Umezawa ES. Evaluation of serological tests to identify Trypanosoma cruzi infection in humans and determine cross-reactivity with Trypanosoma rangeli and Leishmania spp. Clinical and Vaccine Immunology 14: 1045-1049, 2007.

2. Cheng KY, Chang CD, Salbilla VA, Kirchhoff IV, Leiby DA, Schochetman G, Shah DO. Immunoblot assay using recombinant antigens as a supplemental test to confirm the presence of antibodies to Trypanosoma cruzi. Clinical and Vaccine Immunology 14: 355-361, 2007.

3. Gusmão RD, Rezende JM, Rassi A, Gam AA, Neva FA. Antibody Levels to Trypanosoma cruzi in infected patients with and without evidence of chronic Chagas' disease. The American Journal of Tropical Medicine and Hygiene 31: 452-458, 1982.
4. Kirchhoff LV, Gam AA, Gusmao RA, Goldsmith RS, Rezende JM, Rassi A. Increased specificity of serodiagnosis of Chagas' disease by detection of antibody to the 72 and 90-kilodalton glycoproteins of Trypanosoma cruzi. Journal of Infectious Diseases 155: 561-564, 1987.

5. Leiby DA, Wendel S, Takaoka DT, Fachini RM, Oliveira LC, Tibbals MA. Serologic testing for Trypanosoma cruzi: comparison of radioimmunoprecipitation assay with commercially available indirect immunofluorescence assay, indirect hemagglutination assay, and enzyme-linked immunosorbent assay kits. Journal of Clinical Microbiology 38: 639-642, 2000.

6. Luquetti AO, Ponce C, Ponce E, Esfandiari J, Schijman A, Revollo S, Anez N, Zingales B, Ramgel-Aldao R, Gonzalez A, Levin MJ, Umezawa ES, Silveira JF. Chagas' disease diagnosis: a multicentric evaluation of Chagas StatPak, a rapid immunochromatographic assay with recombinant proteins of Trypanosoma cruzi. Diagnostic Microbiology and Infectious Disease 46: 265-271, 2003.

7. Oelemann WM, Vanderborght BO, Costa GCV, Teixeira MGM, Borges-Pereira J, Castro JAF, Coura JR, Stoops E, Hulstaert F, Zrein M, Peralta JM. A recombinant peptide antigen line immunoassay optimized for the confirmation of Chagas' disease. Transfusion 39: 711-717, 1999a.

8. Oelemann WMR, Teixeira MGM, Peralta JM. Screening and Confirmation in Chagas disease serology - A contribution. Memórias do Instituto Oswaldo Cruz 94 (supl I): 307- 308, 1999b

9. Ponce C, Ponce E, Vinelli E, Montoya A, Aguilar V, Gonzalez A, Zingales B, Rangel-Aldao R, Levin MJ, Esfandiari J, Umezawa ES, Luquetti AO, Silveira JF. Validation of a rapid and reliable test for diagnosis of Chagas' disease by detection of Trypanosoma cruzi-specific antibodies in blood of donors and patients in Central America. Journal of Clinical Microbiology 43: 5065-5068, 2005.

10. Sáez-Alquezar A, Luquetti A0, Borges-Pereira J, Moreira EF, Gadelha MFS, GarciaZapata MT, Arruda AHS. Estudo multicentrico. Avaliação do desempenho de conjuntos diagnósticos de IHA, hemaglutinação indireta disponíveis no Brasil, para o diagnóstico sorológico da infecção pelo Trypanosoma cruzi. Revista de Patologia Tropical 26: 343-374, 1997.

11. Sáez-Alquezar A, Sabino EC, Salles N, Chamone DF, Hulstaert F, Npotel H, Stoops E, Zrein M. Serological confirmation of Chagas disease by a recombinant and peptide antigen line immunoassay: INNO-LIA Chagas. Journal of Clinical Microbiology 38: 851-854, 2000.

12. Silveira JF, Umezawa ES, Luquetti AO. Chagas disease: recombinant Trypanosoma cruzi antigens for serological diagnosis. Trends in Parasitology 17: 286-291, 2001.

13. Umezawa ES, Nascimento MS, Kesper NJ, Coura JR, Borges-Pereira J, Junqueira ACV, Camargo ME. Immunoblot Assay Using Excreted-Secreted Antigens of Trypanosoma cruzi in Serodiagnosis of Congenital, Acute, and Chronic Chagas' Disease. Journal of Clinical Microbiology 34: 2143-2147, 1996.

14. Villa L, Morote S, Bernal O, Bulla D, Albajar-Vinas P. Access to diagnosis and treatment of Chagas disease/infection in endemic and non-endemic countries in the XXI century. Memórias do Instituto Oswaldo Cruz 102 (supl I): 87-93, 2007.

15. World Health Organization. Control of Chagas Disease. WHO Technical Report Series 905, World Health Organization, Geneva, 2002.

16. Zauza PL, Borges-Pereira J. Níveis séricos de IgG anti-Trypanosoma cruzi na evolução da cardiopatia chagásica crônica, no período de 10 anos. Revista da Sociedade Brasileira de Medicina Tropical 34: 399-405, 2001. 